\title{
Building Maintenance Practices towards the Common Defects and Resident's Satisfaction of Elderly Homes
}

\author{
Shirley Jin Lin Chua ${ }^{1}$, Cheong Peng Au-Yong ${ }^{2, *}$, Azlan Shah Ali ${ }^{3}$, Mohamad Sufian \\ Hasim 4 \\ ${ }^{1,2,3}$ Centre for Building, Construction \& Tropical Architecture (BuCTA), Faculty of Built \\ Environment, University of Malaya, 50603 Kuala Lumpur, Malaysia. \\ ${ }^{4}$ Faculty of Architecture, Planning, and Surveying, Universiti Teknologi MARA (UiTM), \\ 40450 Shah Alam, Selangor, Malaysia.
}

*auyongcp@um.edu.my

\section{Received: 31 July 2017 Final Version Received: 30 January 2018}

\begin{abstract}
The growing population of elderly globally gives rise to the importance to provide better home for elderly. The homes for elderly need special features to support the decrease in physical to mental capabilities of elderly and enable them to lead an active and well-being lifestyle. Maintenance of this special feature and basic elements in the building play an importance role to ensure the homes are safe to live and will not endanger the users. This research aims to investigate the relationship of maintenance practices (staff behaviours) towards the common defects and resident's satisfaction of elderly homes. Questionnaire survey forms were distributed to the elderly to determine the types of defects and rank the behaviour of maintenance personnel. In addition, semi-structured interview was conducted with the maintenance personnel to validate the current maintenance practice in elderly homes. The findings proven that the behaviours of maintenance personnel were critical to convince the residents in executing the maintenance tasks and to reduce the occurrence of defect. In addition, the findings also proven the maintenance practice for active aging home is differ from usual building maintenance practices. The failure to differentiate the nature of operation could indirectly affect the maintenance performance of the buildings.
\end{abstract}

Keywords: maintenance strategy; building maintenance; elderly; homes; active-aging; staff behaviour; common defect.

\section{INTRODUCTION}

With the ratio of the elderly population (60 years and above) now 1 in 10 persons, estimated to reach 1 in 5 persons by 2050, the aging population has attained a significant position in the world's population demographics and is considered a global phenomenon with far-reaching social and economic ramifications (Sidik et al., 2004). And it is projected that by 2020 , people aged 60 years and above in Malaysia would reach 4 million (Arokiasamy, 1999) from 2.4 million in 2012 (Zawawi, 2013). According to the Department of Statistics (DOS), Malaysia, the proportion of people aged 65 years and over also increased to $5.1 \%$ from $3.9 \%$ in 2000 (Department of Statistics Malaysia (DOS), 2011). Arokiasamy (1999) notes that this proportion is growing faster than the general population.

The Government of Malaysia on January 5, 2011 approved a new National Policy for Older Persons and Plan of Action for Older Persons based on reviews made to the National Policy for Older Persons (1995) and Plan of Action for the Older Persons (1998). The new policy aims to create a conducive environment for older persons who are independent, with dignity, high sense of self-worth and respected by optimising their self-potential through a healthy, positive, active, productive and supportive ageing to lead a well-being life. This is supported by Shahrom and Zainol (2015) that a conducive place to stay is crucial for elderly to promote rehabilitation and make them feel dependable. Six strategies have been outlined in the policy, namely promotion and advocacy, life-long learning, safety and security, governance and shared responsibility, intergenerational solidarity, as well as research and development (Zawawi, 2013).

In Malaysia, the Government, in recognition of this need, formulated the National Policy for Older Persons in October 1995. Programs formulated from the policy to strengthen and care for the aging include providing homes, activity centres, home help services, We Care 
Services - a medium to provide accessibility and transportation for the elderly to access hospitals/clinics for health treatments, financial assistance, lifelong learning, and other benefits such as tax reliefs. Most of these programs are established through the Ministry of Women, Family and Community Development and involve the participation of numerous NGOs across the country (Zawawi, 2013).

In Malaysia, disability and frailty is closely associated with the elderly with their ability to resist or fight illnesses continuously weakened by age (Arokiasamy, 1997). The most common and chronic illnesses in the elderly include cardiovascular disease, cerebrovascular disease, neurological problems, musculoskeletal problems, urinary and faecal incontinence, injuries from accidents, visual and hearing losses, dental deficits, psychosocial problems, depression, dementia, and foot problems (Arokiasamy, 1997). Fausset et al. (2011) further point to a framework called the ecological model of aging developed by Lawton and Nahemow (1973) to illustrate the interaction of person and environment. The framework described the creation of a successful interaction between person and environment where the person has the capabilities to meet the demands of an environment or an environment's demands are reduced to match the capabilities of the person. A maladaptive situation would then occur when either the person's capabilities exceed the environment's demands, or the demands of the environment exceed the person's capabilities.

Buildings could incorporate universal design elements such as ramps, wide door- and hallways, easily accessible electrical controls and switches, lever-style doorknobs and faucets that are easy to use, and one-floor living where there is access to essential rooms without having to use the stairs. In a literature review of physical environments for assisted living (Cutler, 2007), identified various design principles for assisted living facilities. The most recurring attributes had to do with privacy and personal control; accessibility and functional support; and social interaction. Beyond these design attributes and concerns is the operation and maintenance of these buildings. All the facilities provided need to be maintained to support the daily activities of active ageing society. If the facilities are not in an optimum functionality, it may endanger the users particularly the aging population range from decrease in physical to mental capabilities such as decrease in strength, loss of hearing and vision and decline of working memory, etc. In addition, the elderly is found to be prone and with little resistance to illness.

\section{BUILDING MAINTENANCE AND ITS STRATEGIES}

Research on building maintenance in Malaysia has covered various building use types such as office buildings (Au-Yong et al., 2014a, 2014b; Kamaruzzaman et al., 2013), hospital buildings (Rani et al., 2015), educational buildings (Chua et al., 2013, 2015; Lateef et al., 2010a; O. A. A. Lateef et al., 2011), heritage buildings (Abdul Rahman, 2011; Arazi Idrus, 200), and residential buildings (Wahab, 2015). However, building maintenance research targeting active aging homes is lacking.

Many homes require remodelling or retrofitting to accommodate changes in the elderly occupant's mobility (Ball, 2000). The characteristics of the elderly often make them fall into the category of people with special needs some of whom their accommodations are classified as care and or assisted living facilities (Queensland Government, 1999). Seeing that their environment could fluctuate and be as dynamic, the maintenance approach utilised would be of great importance in ensuring the best building environment for the elderly. Fausset et al. (2011) note that, the elderly's home environment requires predictable maintenance such as changing furnace filters, cleaning floors, replacing light bulbs, and mowing the lawn. Despite unpredictable environmental incidents such as a storm ripping off the roof, a predictive maintenance approach is seen impacting on how quickly and efficiently such unpredictable maintenance requirements could be attended to and rectified. Holistically, there is hardly any empirical evidence for the appropriate maintenance approaches to aging homes. Kelly et al. (2014) discussing home maintenance of aging people, focused on the maintenance tasks the resident elderly occupants could perform. Utilising the Selection, Optimisation, and Compensation (SOC) model, they found that older adults would be most likely to manage common agerelated difficulties by using tools and technologies and suggested the designing and manufacturing of easy-to-use tools that could alleviate difficulties faced around the home. Finding the right combination for homes of the elderly requires a good understanding of the characteristics of the aging and their home functional requirements, which is key to planning and implementation of a successful 
maintenance strategy for aging homes. In the literature, characteristics and challenges of the aging population have been identified along with the nature of accommodation that should house them. Challenges to providing the most conducive physical environment for aging people include how these accommodations could be appropriately maintained. Several maintenance strategies with specific usefulness for various and certain scenarios have been identified. Finding the right combination for homes of aging people requires a good understanding of the characteristics of the aging population and their home functional requirements. There is suggestion that planned pro-active maintenance is the appropriate maintenance approach for homes housing elderly people. The extent to which the aging population's needs are taken into consideration while planning and designing maintenance approaches would determine the extent of a successful maintenance implementation.

Maintenance basically is any action performed to ensure the required functionality of an item. Moreover, this applies to buildings as well. The British Standard 3811 of 1993 defines maintenance as "the combination of all technical and administrative actions, including supervision actions, intended to retain an item in, or restore it to, a state in which it can perform a required function" (Wood, 2003). O. A. A. Lateef et al. (2011) contend that, a conclusive definition of maintenance provided by Lateef et al. (2010a) entails "processes and services to preserve, repair, protect and care for a building's fabric and engineering services after completion, repair, refurbishment or replacement to current standards to enable it to serve its intended functions throughout its entire life span without drastically upsetting its basic features and use". Traditionally, the objectives of building maintenance include (El-Haram \& Horner, 2002):

- to ensure that the buildings and their associated services are in a safe condition;

- to ensure that the buildings are fit for use;

- to ensure that the condition of the building meets all statutory requirements;

- to carry out the maintenance work necessary to maintain the value of the physical assets of the building stock; and

- to carry out the work necessary to maintain the quality of the building.
While maintenance activities are performed on the building itself, there is a contention that maintenance should be viewed from the perspective of how the building fulfil its functions to occupants and users (Ab Wahab \& Basari, 2013; O. A. A. Lateef et al., 2011). By making occupants and users the objective of building maintenance where the building is capable of providing the users with the best environment to perform their functions, (O. A. Lateef et al., 2011) contend that, optimum value could be derived from the functioning of the building. This also is the basis for maintenance management. A well implemented maintenance management strategy minimises the risk of a major failure (Rani et al., 2015).

Maintenance falls generally into two categories, namely planned and unplanned maintenance. Under these two categories falls the various types or approaches to maintenance. planned maintenance is thought out, documented, monitored and executed in an organised manner. Unplanned maintenance is the direct opposite. There is no plan whatsoever to this type of maintenance. Unplanned maintenance is basically of reactive and corrective nature and is divided into emergency maintenance and corrective maintenance (Ahn \& Kim, 2011). All other approaches to maintenance, including corrective maintenance and emergency maintenance fall under planned maintenance.

\section{- Pro-active maintenance}

Proactive maintenance detects failure from its source and its main purpose is to extend the useful life of a component to the extent possible by adopting a high level of mastery with respect to operating precision (Jabar, 2003). It is noted that pro-active maintenance is not the same as preventive or predictive maintenance as preventive maintenance is aimed at completely preventing the occurrence of a failure and predictive maintenance utilises usually statistical modelling based on component information to predict when and how a failure incident might occur.

\section{- Preventive maintenance}

This approach involves carrying out measures to avoid or limit the probability of failure incidents and is designed to combat the shortcomings of corrective maintenance (Horner et al., 1997). Measures are taken to service or replace components before failure could occur. This type of approach is further broken commonly into two forms: scheduled 
preventive maintenance and condition-based preventive maintenance. Scheduled preventive maintenance is carried out on the item or component based on a scheduled period, which could be usage or time based (Au-Yong et al., 2016), while condition-based preventive maintenance is initiated based on the actual condition of the item or component as recorded from constant monitoring (Au-Yong et al., 2014a).

\section{- Corrective maintenance}

This is an action carried out to restore a component that has already failed. It is intended to return the component to a condition that it satisfactorily performs its required function. It is the simplest form of maintenance but can be costly due to the tendency of component failure leading to large amount of consequential to other building elements (Horner et al., 1997). In addition, the uncertainty and inconvenience of component failure is also a huge area of concern. Despite these disadvantages, elements that are cheaper to replace than repair could benefit from this type of maintenance approach. Furthermore, this type of maintenance approach is only appropriate when the cost of preventive measures is not justified by the impact of a failure, meaning the consequences of failure are negligible or insignificant.

\section{- Predictive maintenance}

Predictive maintenance utilises usually statistical modelling based on component information to predict when and how a failure incident might occur. It is closely related to condition-based maintenance, and indeed utilises condition-based maintenance measurement and monitoring techniques such as vibration analysis, infrared thermographs, ultrasonic detection (Jabar, 2003) and it involves equipment inspections during both running and stoppage periods (Onawoga \& Akinyemi, 2010).

\section{- Emergency maintenance}

This approach is employed to rectify issues that might result into disastrous failures or serious consequences (Au-Yong et al., 2014b). For example, a gas pipe leak within a house would require an emergency rectification to prevent the possibility of a major fire outbreak. In summary, Rani et al. (2015) note that it is essential to adopt a balanced approach in maintenance strategy planning as all the maintenance types have different functions and are useful for a variety of circumstances, however, emphasising the relevance of preventive maintenance. They argue that preventive maintenance provides a proper schedule for maintaining the facilities and its helps maintenance management and cost planning.

\section{METHODOLOGY}

The research adopted mixed method approach where questionnaire survey was conducted with the residents staying at two different homes for the elderly and semi-structured interviews were conducted with the maintenance personnel of elderly homes. The first elderly home managed by wakaf (private donation) runs by private organisation. On the other hand, the second case managed by responsible government agencies. The residents were asked to rate the frequency of occurrence of the defects in the building and the satisfaction level towards the behaviours of maintenance personnel. Likert scale rating system was employed with fivepoint scale from strongly disagree to strongly agree. A total of 60 valid questionnaires (fully completed) were filtered to be valid for data analysis purpose. Whereby, random sampling method was done by distributing questionnaire of one of the occupants in every occupied units of the elderly homes. The random sampling method ensures high generalisability, where everyone in the research population has equal chance of being selected for the questionnaire survey. The analysis method adopted for identifying the rank of defect occurrence and maintenance personnel behaviours was mean analysis. Besides, correlation analysis was also conducted to establish the relationship between maintenance personnel behaviours with the overall defect and resident's confidence towards the personnel.

In addition, semi-structured interview was conducted with the maintenance personnel of the elderly home to investigate how the maintenance of elderly home was carried out. The collected information was used to further elaborate the result of questionnaire survey.

\section{RESULTS AND DISCUSSION}

The types of defect were investigated by identifying their occurrence in dwelling units of Building A (Temerloh) and B (Seri Kenangan). In order to ensure reliability of the data, reliability analysis was conducted for the defect variables. The purpose of this analysis was to check the consistency of the scale of data 
(Leech et al., 2011). Cronbach's alpha coefficient tests showed the coefficients for defects of Building A and B were 0.779 and 0.930 respectively. Coefficient of more than 0.70 indicates good reliability (Leech et al., 2011). Then, ranking analysis was adopted to identify the defects' rank based on the mean score. The results were tabulated in Table 1 and 2 for case study in Building $\mathrm{A}$ and $\mathrm{B}$ respectively.
In Building $\mathrm{A}$, the highest ranked defect was about the functionality of lockset for door, with a mean score of 4.30 (see Table 1). The high occurrence of defective lockset was due to lack of maintenance. Basically, the defective lockset did not possess any safety risk to the residents. Thus, lack of priority and attention were given to maintenance of the item. However, it might possess security risk when defective lockset occurs on the main access of the dwelling unit. Whereby, trespassing issue can happen easily and leads to the thieving case.

Table 1: Ranking analysis of defect occurrence (Building A)

\begin{tabular}{llcc}
\hline Rank & Defect & Mean $(\mathrm{n}=30)$ & Std. Deviation \\
\hline 1 & Functionality of lockset for door & 4.30 & .877 \\
2 & Ease of opening \& closing & 4.10 & 1.185 \\
3 & Evenness of surface & 2.70 & 1.317 \\
4 & Patchy \& rough surface & 2.40 & 1.429 \\
5 & Stain mark & 2.13 & 1.279 \\
6 & Missing/defective of accessories & 1.80 & 1.375 \\
7 & Variance in length of threads and risers for staircases & 1.67 & 1.061 \\
8 & Dampness & 1.63 & 1.098 \\
9 & Minor crack & 1.47 & .900 \\
10 & Major crack & 1.40 & .770 \\
11 & Falls in wet areas & 1.33 & .844 \\
12 & Termite attack & 1.30 & .596 \\
\hline
\end{tabular}

Table 2: Ranking analysis of defect occurrence (Building B)

\begin{tabular}{llcc}
\hline Rank & Defect & Mean $(\mathrm{n}=30)$ & Std. Deviation \\
\hline 1 & Ease of opening \& closing & 2.60 & 1.163 \\
2 & Falls in wet areas & 2.53 & .973 \\
3 & Functionality of lockset for door & 2.47 & 1.137 \\
4 & Stain mark & 2.43 & 1.194 \\
5 & Patchy \& rough surface & 2.40 & 1.192 \\
6 & Evenness of surface & 2.40 & 1.133 \\
7 & Missing/defective of accessories & 2.37 & 1.098 \\
8 & Minor crack & 2.33 & 1.028 \\
9 & Variance in length of threads and risers for staircases & 2.30 & 1.088 \\
10 & Major crack & 1.90 & .885 \\
11 & Dampness & 1.83 & .874 \\
12 & Termite attack & 1.60 & .724 \\
\hline
\end{tabular}

Next, the defect found to be ranked in second was regarding the ease of opening and closing, with mean score of 4.10 (see Table 1). Like the first-ranked defect, the ease of opening and closing was affected by lack of maintenance. Greasing or lubricating the door and window hinges was supposed to be a routine maintenance task to ensure the ease of opening and closing. Whereby, the elderly would face difficulty to open or close the door and window if the maintenance task is not carried out regularly. Thus, this task is critical to ensure the smooth opening and closing for the elderly.

In Building B, all the investigated defects were not obvious, which all their mean scores were 
less than 3.00 (see Table 2). Therefore, the maintenance execution in this building was considered good. Overall, the residents satisfied with the conditions of their dwelling units.

In comparison of both buildings, the higher ranked defects were minor defects that did not create any harmful issues to the residents in terms of safety and health. Nevertheless, all the defects should be tackled promptly to avoid further deterioration that may bring up harmful issues in the future. The maintenance personnel should take the responsibility to execute their tasks promptly, as the elderly who stay in the dwelling unit most of the time are more prone to be affected by the defects. Preventive maintenance or regular inspection is recommended to ensure that all the defects can be rectified timely (Au-Yong et al., 2016).

The semi-structured interviews with management of buildings show that repair works would be carried out based on complaint made by the occupants. However, the response time could be longer depending on availability of in-house maintenance personnel. This problem occurred due to limitation on funding allocation for maintenance resources. Although funding to manage elderly home for Building B provided by the government, most of the portions were allocated to run activities for the occupants. Less than 10 per cent from yearly total allocation used for maintenance related activities. Similarly, for Building A, all operational cost depends on public donation, which is very limited and unpredictable. Maintenance activities mostly would be least prioritised compared to other activities. As a result, corrective and ad-hoc maintenance strategy was implemented for the building. Limited maintenance budget also induces to low salary for maintenance staffs, which could act as de-motivators factor. Consequently, many backlogs on repair works recorded for both case studies.

The semi-structured interviews also suggest that a low level of skill and knowledge of the maintenance workers would contribute to rework to some maintenance works. This would contribute to a high overall maintenance cost, which is not good for an elderly home. The management of buildings could be mistaken in thinking that the approach in managing elderly homes is the similar as managing other buildings. It could be argued that managing elderly homes is differ in many ways. Every elderly home is different in occupants' background and character, which poses different issues and difficulties processed. The failure to differentiate between these natures of operation could end up with lack in approach used, which indirectly affects the maintenance performance of the buildings.

With regards to formal training for maintenance personnel, the semi-structured interviews with both building management personnel also indicates that the workers believed that the experience they obtained during the on-job is sufficient to provide skill and understanding to handle maintenance works. Therefore, it was not considered necessary for maintenance workers to attend formal training in order to gain the required knowledge. The maintenance service quality provided by the in-house workers however could be affected with limited funding. The management of buildings would put limit to maintenance expenditure includes to buy parts and consumables. As a result, low quality parts would be chosen for cheap and short-term solution of any maintenance problems. Conversely, anything concerning monetary savings would result in a decrease in the quality of maintenance works.

Taking into cognisance the significance of maintenance personnel, the study also examined the behaviours of maintenance personnel. The reliability analysis was conducted to test the reliability of data on the maintenance personnel behaviours. Cronbach's alpha coefficient tests showed the coefficients for maintenance personnel behaviours of Building A and B were 0.944 and 0.979 respectively. Therefore, the consistencies of scale of the data were deemed excellent. Subsequently, Table 3 and 4 ranked the maintenance personnel behaviours of Building A and B respectively.

Overall, the behaviours of maintenance personnel in both buildings were above average, being evaluated by the residents. All the mean scores were above 3.00, yet, below 4.00 (see Table 3 and 4). So, there is a space of improvement for the maintenance personnel. In fact, the elderly relies more on the maintenance personnel to carry out the maintenance activities, because they are incapable to do such works by themselves. Even if they do, this can be quite dangerous when accident happens on them. Therefore, skilful and responsive maintenance personnel are essentially required in the elderly home. 
Table 3: Ranking analysis of maintenance personnel behaviours (Building A)

\begin{tabular}{llcc}
\hline Rank & \multicolumn{1}{c}{ Behaviour } & Mean (n=30) & Std. Deviation \\
\hline 1 & Work environment being still comfort and habitable while working & 3.77 & .568 \\
2 & $\begin{array}{l}\text { Residents feel safe while the workers carry out the works in the } \\
\text { resident's unit }\end{array}$ & 3.77 & .679 \\
\hline \multicolumn{2}{l}{} & & \\
\hline 3 & Provide correct and necessary information to residents before work & 3.77 & .568 \\
4 & Appropriate, accurate and clear communication to residents during & 3.73 & .583 \\
& works & & \\
5 & Staff have knowledge to answer resident's enquiries & 3.70 & .651 \\
6 & Operating hours convenient to residents & 3.70 & .794 \\
7 & Prompt response to resident's requests & 3.67 & .661 \\
8 & Cleanliness and tidiness after repair works & 3.60 & .724 \\
9 & Staff complete the work within the time schedule & 3.53 & .973 \\
\hline
\end{tabular}

Table 4: Ranking analysis of maintenance personnel behaviours (Building B)

\begin{tabular}{llcc}
\hline Rank Behaviour & Mean (n=30) & Std. Deviation \\
\hline 1 & Staff complete the work within the time schedule & 3.33 & 1.155 \\
2 & Cleanliness and tidiness after repair works & 3.27 & 1.048 \\
3 & Staff have knowledge to answer resident's enquiries & 3.13 & 1.106 \\
4 & Work environment being still comfort and habitable while working & 3.13 & 1.008 \\
5 & Residents feel safe while the workers carry out the works in the & 3.10 & 1.029 \\
& resident's unit & & \\
6 & Appropriate, accurate and clear communication to residents during & 3.10 & .995 \\
& works & & \\
7 & Operating hours convenient to residents & 3.07 & 1.048 \\
8 & Provide correct and necessary information to residents before work & 3.03 & .964 \\
9 & Prompt response to resident's requests & 3.00 & 1.083 \\
\hline
\end{tabular}

Furthermore, the maintenance personnel behaviours were extended to analyse using correlation analysis with the overall defect and resident's confidence towards the personnel. Theoretically, correlation coefficient of less than 0.3 points to a weak relationship; a coefficient of 0.3 to 0.5 denotes a moderate relationship; and a correlation coefficient of 0.5 or more points to a strong relationship between two variables (Gray, 2012). Meanwhile, SPSS determines significantly correlated variables with the significance value of 0.05 or below. The analysis results were shown in Table 5 and 6 for case study in Building $A$ and B respectively. Indeed, two assumptions were made for the analysis and the analysis results were expected as follows:

(a) If the satisfaction towards the personnel behaviour is higher, the rating of overall defect is lower. (expected negative correlations) (b) If the satisfaction towards the personnel behaviour is higher, the resident's confidence towards them is higher. (expected positive correlation)

The analysis result of Building A revealed that there were no significant relationships between the maintenance personnel behaviours and overall defect rating (see Table 5). It did not meet the first assumption of the study. Whereby, the maintenance works in the dwelling units of Building A were indeed liable by the residents themselves. The residents might delay in calling the maintenance contractor to attend the defect. As a result, the defect continued deteriorating and remained unattended. The delayed action by residents manipulated the relationship between behaviours of maintenance personnel and overall defect rating. 
Table 5: Correlation analysis of maintenance personnel behaviours with the overall defect and resident's confidence towards the personnel (Building A)

\begin{tabular}{|c|c|c|c|c|}
\hline & \multicolumn{2}{|c|}{ Overall defect } & \multicolumn{2}{|c|}{$\begin{array}{l}\text { Resident's confidence } \\
\text { towards the personnel }\end{array}$} \\
\hline & $\begin{array}{l}\text { Correlation } \\
\text { Coefficient }\end{array}$ & $\begin{array}{c}\text { Sig. } \\
(2-\text { tailed })\end{array}$ & $\begin{array}{l}\text { Correlation } \\
\text { Coefficient }\end{array}$ & $\begin{array}{c}\text { Sig. } \\
(2 \text {-tailed })\end{array}$ \\
\hline Staff complete the work within the time schedule & .061 & .750 & $.684^{* *}$ & .000 \\
\hline Operating hours convenient to residents & -.062 & .745 & $.738^{* *}$ & .000 \\
\hline $\begin{array}{l}\text { Provide correct and necessary information to } \\
\text { residents before work }\end{array}$ & .001 & .996 & $.810^{* * *}$ & .000 \\
\hline $\begin{array}{l}\text { Appropriate, accurate and clear communication to } \\
\text { residents during works }\end{array}$ & -.042 & .824 & $.758^{* *}$ & .000 \\
\hline Cleanliness and tidiness after repair works & -.058 & .762 & $.534^{* *}$ & .002 \\
\hline $\begin{array}{l}\text { Residents feel safe while the workers carry out the } \\
\text { works in the resident's unit }\end{array}$ & -.142 & .453 & $.618^{* *}$ & .000 \\
\hline $\begin{array}{l}\text { Work environment being still comfort and habitable } \\
\text { while working }\end{array}$ & -.090 & .635 & $.810^{* *}$ & .000 \\
\hline Prompt response to resident's requests & -.061 & .747 & $.815^{* *}$ & .000 \\
\hline Staff have knowledge to answer resident's enquiries & -.171 & .366 & $.811^{* *}$ & .000 \\
\hline
\end{tabular}

On the other hand, all personnel behaviours were positively and significantly correlated to resident's confidence towards the personnel. The result confirmed the second assumption of the study. The positive behaviours of maintenance personnel convinced the residents for the implementation of the maintenance activities in the dwelling units.

In Building $\mathrm{B}$, the dwelling units were managed and maintained by an in-house maintenance team. Whereby, the maintenance tasks in the dwelling units were liable by the maintenance team. The residents would lodge complaint or report when the defect was spotted. Additionally, the maintenance personnel would inspect the dwelling units regularly to ensure that the defect would be remedied timely. The analysis result in Table 6 verified both the assumptions of study. All behaviours of maintenance personnel were negatively and significantly correlated to overall defect rating; while positively and significantly correlated to resident's confidence towards the personnel. Hence, the result validated that the behaviours of maintenance personnel were critical to convince the residents in executing the maintenance tasks and to reduce the occurrence of defect.

Table 6: Correlation analysis of maintenance personnel behaviours with the overall defect and resident's confidence towards the personnel (Building B)

\begin{tabular}{|c|c|c|c|c|}
\hline & \multicolumn{2}{|c|}{ Overall defect } & \multicolumn{2}{|c|}{$\begin{array}{l}\text { Resident's confidence } \\
\text { towards the personnel }\end{array}$} \\
\hline & $\begin{array}{l}\text { Correlation } \\
\text { Coefficient }\end{array}$ & $\begin{array}{r}\text { Sig. } \\
\text { (2-tailed) }\end{array}$ & $\begin{array}{l}\text { Correlation } \\
\text { Coefficient }\end{array}$ & $\begin{array}{r}\text { Sig. } \\
\text { (2-tailed) }\end{array}$ \\
\hline Staff complete the work within the time schedule & $-.548^{* *}$ & .002 & $.683^{* *}$ & .000 \\
\hline Operating hours convenient to residents & $-.543^{* *}$ & .002 & $.826^{* *}$ & .000 \\
\hline $\begin{array}{l}\text { Provide correct and necessary information to residents } \\
\text { before work }\end{array}$ & $-.663^{* *}$ & .000 & $.764^{* *}$ & .000 \\
\hline $\begin{array}{l}\text { Appropriate, accurate and clear communication to } \\
\text { residents during works }\end{array}$ & $-.655^{* *}$ & .000 & $.740^{* *}$ & .000 \\
\hline Cleanliness and tidiness after repair works & $-.504^{* *}$ & .005 & $.764^{* *}$ & .000 \\
\hline $\begin{array}{l}\text { Residents feel safe while the workers carry out the } \\
\text { works in the resident's unit }\end{array}$ & $-.613^{* *}$ & .000 & $.713^{* *}$ & .000 \\
\hline
\end{tabular}




\begin{tabular}{|c|c|c|c|c|}
\hline $\begin{array}{l}\text { Work environment being still comfort and habitable } \\
\text { while working }\end{array}$ & $-.644^{* *}$ & .000 & $.716^{* *}$ & .000 \\
\hline Prompt response to resident's requests & $-.635^{* *}$ & .000 & $.712^{* *}$ & .000 \\
\hline Staff have knowledge to answer resident's enquiries & $-.411^{*}$ & .024 & $.848^{* *}$ & .000 \\
\hline
\end{tabular}

*. Correlation is significant at the 0.05 level (2-tailed).

**. Correlation is significant at the 0.01 level (2-tailed)

\section{CONCLUSION}

The characteristics and challenges of the aging population have been identified along with the nature of accommodation that should house them. Challenges to providing the most conducive physical environment for aging people include how these places could be appropriately maintained. Several maintenance strategies with specific usefulness for various and certain scenarios have been identified. Finding the right combination for homes of aging people requires a good understanding of the characteristics of the aging population and their home functional requirements. The extent to which the aging population's needs are taken into consideration while planning and designing maintenance approaches would determine the extent of a successful maintenance implementation.

\section{ACKNOWLEDGEMENT}

The authors gratefully acknowledge the financial support of the University of Malaya Living Lab Grant Programme (UMLLGP), No. LL00615SUS established at the University of Malaya, Sustainability Science Research Cluster.

\section{REFERENCES}

Ab Wahab, Y., \& Basari, A. S. H. (2013). Building Maintenance Management Preliminary Finding of a Case Study in Icym. Middle-East Journal of Science Research, 1260-1268.

Abdul Rahman, M. A. a. A., Zainal Abidin and Abdullah, Mohd Sufyan and Musa, Mohd Kamaruzaman. (2011). Issues and problems affecting the implementation and effectiveness of heritage buildings maintenance. Paper presented at the The International Conference on Civil and Environmental Engineering Sustainability (IConCEES 2011), Johor Bahru, Malaysia.

Ahn, S., \& Kim, W. (2011). On determination of the preventive maintenance interval guaranteeing system availability under a periodic maintenance policy. Structure and Infrastructure Engineering, 7(4), 307-314.

Arazi Idrus, F. K., Mahmoud Sodangi. (200). Maintenance Management Framework for
Conservation of Heritage Buildings in Malaysia. Modern Applied Science, 4(11), 66.

Arokiasamy, J. (1999). Malaysia's ageing population: challenges in the new millennium. Medical Journal of Malaysia, 54(4), 429-432.

Arokiasamy, J. T. (1997). Malaysia's Ageing Issues Medical Journal of Malaysia, 52(3), 197-201.

Au-Yong, C. P., Ali, A. S., \& Ahmad, F. (2014a). Improving occupants' satisfaction with effective maintenance management of HVAC system in office buildings. Automation in Construction, 43, 31-37.

Au-Yong, C. P., Ali, A. S., \& Ahmad, F. (2014b). Optimising Maintenance Cost Performance with Skilled Technicians. Structural Survey, 32(3), 238-245.

Au-Yong, C. P., Ali, A. S., \& Ahmad, F. (2016). Enhancing building maintenance cost performance with proper management of spare parts. Journal of Quality in Maintenance Engineering, 22(1), 51-61.

Ball, M. S. (2000). Ageing in Place: A Toolkit for Local Governments. Atlanta, GA: Community Housing Resource Center Press.

Chua, S. J. L., Ali, A. S., \& Alias, A. B. (2013). An Analytic Hierarchy Process (AHP) Decision Making Framework for Procurement Strategy Selection in Building Maintenance Work. Journal of Performance of Constructed Facilities.

Chua, S. J. L., Ali, A. S., \& Alias, A. B. (2015). Implementation of Analytic Hierarchy Process (AHP) decision making framework for building maintenance procurement selection: Case study of Malaysian public universities. Eksploatacja i Niezawodnosc Maintenance and Reliability, 17(5), 7-18.

Cutler, L. J. (2007). Physical Environments of Assisted Living: Research Needs and Challenges. The Gerontologist, 47(3), 68-82.

Department of Statistics Malaysia (DOS). (2011). Population Distribution and Basic Demographic Characteristic Report 2010. Retrieved May 6, 2016, from https://www.statistics.gov.my/index.php?r=c olumn/ctheme\&menu_id=LOpheU43NWJwR WVSZklWdzQ4TlhUUT09\&bul_id=MDMx dHZjWTk1SjFzTzNkRXYzcVZjdz09\# 
El-Haram, M. A., \& Horner, M. W. (2002). Factors affecting housing maintenance cost. Journal of Quality in Maintenance Engineering, 8(2), 115-123.

Fausset, C. B., Kelly, A. J., Rogers, W. A., \& Fisk, A. D. (2011). Challenges to Aging in Place: Understanding Home Maintenance Difficulties. Journal of housing for the elderly, 25(2), 125-141.

Gray, C. D., \& Kinnear, P. R. (2012). IBM SPSS Statistics 19 Made Simple. East Sussex: Pyschology Press.

Horner, R. M. W., El-Haram, M. A., \& Munns, A. K. (1997). Building maintenance strategy: a new management approach. Journal of Quality in Maintenance Engineering, 3(4), 273-280.

Jabar, H. (2003). Plant maintenance strategy: key for enhancing profitability. doi:http://www.maintenanceresources.com/re ferencelibrary/ezine/chemclean.htm

Kamaruzzaman, S. N., Myeda, N. E., \& Pitt, M. (2013). Performance levels of high-rise private office buildings maintenance management in Malaysia. Eksploatacja $i$ Niezawodność, 15(2), 111-116.

Kelly, A. J., Fausset, C. B., Rogers, W., \& Fisk, A. D. (2014). Responding to Home Maintenance Challenge Scenarios. Journal of Applied Gerontology, 33(8), 1018-1042.

Lateef, O. A., Idrus, A., \& Khamidi, M. F. (2011). Investigating building maintenance practices in Malaysia: a case study. Structural Survey, 29(5), 397-410.

Lateef, O. A., Khamidi, M. F., \& Idrus, A. (2010a). Building maintenance management in a Malaysian university campuses: a case study. Australasian Journal of Construction Economics and Building, 10(1/2), 76-89.

Lateef, O. A. A., Khamidi, M. F., \& Idrus, A. (2011). Appraisal of the building maintenance management practices of Malaysian universities. Journal of Building Appraisal, 6, 261-275.

Lawton, M., \& Nahemow, L. (1973). Ecology and the aging process. In P. L. M. Eisdorfer C (Ed.), he Psychology of Adult Development and Aging (pp. 619-674). Washington, D.C: The American Psychological Association.

Leech, N. L., Barrett, K. C., \& Morgan, G. A. (2011). IBM SPSS for Intermediate Statistics: Use and Interpretation (4th ed.). New York: Taylor and Francis Group, LLC.

Onawoga, D. T., \& Akinyemi, O. O. (2010). Development of equipment maintenance strategy for critical equipment. The Pacific Journal of Science and Technology, 11(1), 328-342.

Queensland Government. (1999). Design Guidelines for Queensland Residential Aged
Care Facilities. Brisbane, Australia: Queensland Government.

Rani, N. A. A., Baharum, M. R., Akbar, A. R. N., \& Nawawi, A. H. (2015). Perception of Maintenance Management Strategy on Healthcare Facilities. Procedia - Social and Behavioral Sciences, 170, 272-281.

Shahrom, S. K., \& Zainol, R. (2015). Universal design in housing for people with disabilities: A review. Journal of Design and Built Environment, 15(1), 33-42.

Sidik, S. M., Rampal, L., \& Afifi, M. (2004). Physical and Mental Health Problems of the Elderly in a Rural Community of Sepang, Selangor. The Malaysian Journal of Medical Sciences : MJMS, 11(1), 52-59.

Wahab, S. R. H. A., Ani, A. I. C., Sairi, A., Hussain, A. H., \& Surat, M. (2015). Parameters issues of building maintenance management at high rise residential building: a review. Australian Journal of Basic and Applied Sciences, 9(7), 143-146.

Wood, B. (2003). Building Care. Oxford, UK: Blckwell Publishing.

Zawawi, R. B. H. (2013). Active Ageing in Malaysia. Paper presented at the The Second Meeting of the Committee on "International Cooperation on Active Ageing", Tokyo, Japan. 